\title{
The Effects of Lower Limb Training Using Sliding Rehabilitation Machine on the Foot Motion and Stability in Stroke Patients
}

\author{
Kwan-Sub Lee', Kyoung Kim², Na-Kyung Lee ${ }^{3}$ \\ 'Department of Physical Therapy, Kang Hospital, Daegu; ${ }^{2}$ Department of Physical Therapy, College of Rehabilitation Science, Daegu University, \\ Gyeongsan; ${ }^{3}$ Department of Rehabilitation Science, Graduate School, Daegu University, Gyeongsan, Korea
}

Purpose: The purpose of this study was to investigate the effect of lower limb training using a sliding rehabilitation machine on the foot motion and stability in stroke patients.

Methods: Thirty participants were allocated to two groups: Training group $(n=15)$ and Control group $(n=15)$. Subjects in the control group received physical therapy for 30 minutes, five times per week, and those in the training group received lower limb training using a sliding rehabilitation machine for 30 minutes, five times per week, with physical therapy for 30 minutes, five times per week, during a period of six weeks. Heel rotation, hallux stiffness, foot balance, metatarsal load, toe out angle, and subtalar joint flexibility were measured by RS-scan.

Results: Significant improvement of the foot motion (hallux stiffness, meta load) and the foot stability (toe out angle, subtalar joint flexibility) was observed in the training group.

Conclusion: This study demonstrated that lower limb training using a sliding rehabilitation machine is an effective intervention to improve the foot motion and stability.

Keywords: Stroke, Sliding rehabilitation machine, Foot stability

\section{서 론}

뇌졸중은 뇌의 여러 영역으로 산소와 글루코스를 공급하는 뇌혈관 의 손상으로 인한 뇌신경세포의 괴사로 인하여 발생하고, ${ }^{1}$ 뇌졸중 발 병 후 환자의 $40 \%$ 에서 기능적 장애, $15-30 \%$ 에서 심각한 장애가 발생 하게 된다. ${ }^{2}$ 뇌졸중의 발생 빈도는 지속적으로 증가하고 있으며, 적극 적인 물리치료와 중재에도 불구하고 운동, 감각, 인지, 지각 등의 현저 한 장애를 동반한다. ${ }^{3,4}$ 뇌졸중에 의한 편마비 환자에서는 마비측에 대한 중추신경계의 조절 능력이 소실되며, 주동근과 길항근의 부조 화를 보인다. 특히 마비측의 하지 근력 약화로 인하여 보행능력의 감 소를 동반하여 독립성을 저하시키고 결과적으로 사회 참여에 제약 을 가져오게 된다. ${ }^{5}$ 따라서 뇌졸중 환자들의 기능회복을 극대화하고 삶의 질을 향상시키기 위해 하지 근력 강화는 필수적이다. ${ }^{5-7}$

뇌졸중 환자의 하지 근력을 회복하는 방법에는 탄력밴드, ${ }^{8}$ 등속성 기구 ${ }^{9}$ 부하자전거 타기,,$^{10}$ 공압식 저항운동기구 ${ }^{11}$ 등을 이용한 방법이 있으며, 저항 양에 따라 저강도 저항운동, ${ }^{12}$ 고강도 저항운동, ${ }^{6}$ 그리고
점진적으로 저항을 증가시키는 점진적 저항운동 방법이 실시된다. ${ }^{11}$ 또한 저항운동 방법에 따라 열린 사슬 운동과 닫힌 사슬 운동으로 구분된다. 열린 사슬 운동은 사지의 원위부에서 자유롭게 움직이는 운동방법으로 관절가동범위가 제한된 환자의 근력강화를 위해 중요 한 운동 방법이다. 닫힌 사슬 운동은 사지의 원위부가 고정되어 있는 상태에서 근위부와 원위부에서 저항을 동시에 적용할 때 일어나는 운동으로 동적인 근육의 전단력을 감소시켜 관절의 안정성을 주고, 기계적 수용기는 관절낭의 압력의 변화에 민감하게 반응하여 고유 수용성 감각을 촉진하는 장점을 갖게 된다. ${ }^{13}$ 특히 최근에는 슬라이 딩 재활훈련기를 이용한 닫힌 사슬 방법의 저항운동이 근력강화 및 균형능력, 협응력 강화에 도움이 되는 것으로 연구되었다. 이로 인하 여 선행연구에서는 저항운동 방법에 따른 운동 효과 및 정상보행에 미치는 영향에 대한 다양한 연구가 실시되어 왔다.13,14

정상적인 보행에서 발과 발목 관절은 인체 정렬에 중요한 역할을 하게 되며, 많은 관절과 복잡한 구조의 형태를 가지고 있는 부위로 삼 차원적인 공간 내에서 운동하는 분절이다. 15,16 직립형태의 선 자세나, 
보행 시 인체는 비교적 적은 지지면과 높은 신체중심을 이뤼 태생적 으로 불안정한 자세를 유지하게 된다. 또한 보행을 하는 일련의 과정 에서 발의 회내 및 회외, 외전 및 내전, 배측 굴곡 및 저측 굴곡 양이 적절한가에 따라 발목의 안정성을 좌우하게 되고 결과적으로 얼마 나 안정적인 보행을 할 수 있는지 결정하게 된다. ${ }^{4}$ 따라서 발의 움직 임과 안정성은 보행을 평가하는데 중요한 변수이며, 특히 뇌 손상으 로 인하여 운동 및 감각 장애를 동반하고 이로 인하여 보행 능력이 저 하된 뇌졸중 환자의 발의 움직임과 안정성에 대한 연구는 중요하다.

그러나 건강한 성인에서 근력운동 및 체중 부하 방법에 따른 발의 안정성과 운동학적 분석에 대한 연구는 많이 발표 되었지만, 뇌졸중 환자를 대상으로 슬라이딩 재활훈련기를 이용한 하지훈련이 발의 움직임과 안정성에 미치는 영향에 대한 연구는 부족한 실정이다. 따 라서 본 연구는 뇌졸중 환자를 대상으로 슬라이딩 재활훈련기를 이 용한 하지 운동이 발의 움직임 및 안정성에 어떠한 영향을 미치는지 확인하고, 뇌졸중 환자의 임상치료에 있어 더욱 효과적인 방법을 제 시하고자 한다.

\section{연구방법}

\section{1. 연구대상}

본 연구는 2013년 12월부터 2014년 2월까지 대구 소재 K병원에서 물 리치료를 받고 있는 환자 중 연구에 참여하기로 동의하고 연구 조건 을 충족하며, 뇌졸중으로 진단받은 편마비 환자 30 명(남자 16 명, 여자 14 명)을 대상으로 하였다. 대상자의 선정기준은 뇌졸중으로 인하여 편마비 진단 받은 자, 발병기간이 6개월 이상인자, 보조 또는 도움 없 이 $10 \mathrm{~m}$ 독립적인 보행이 가능한 자, MMSE-K 점수가 24점 이상인 자, 시야결손 및 전정기관에 이상이 없는 자, 체간과 양 하지에 정형외과 적 질환이 없는 자로 하였다.

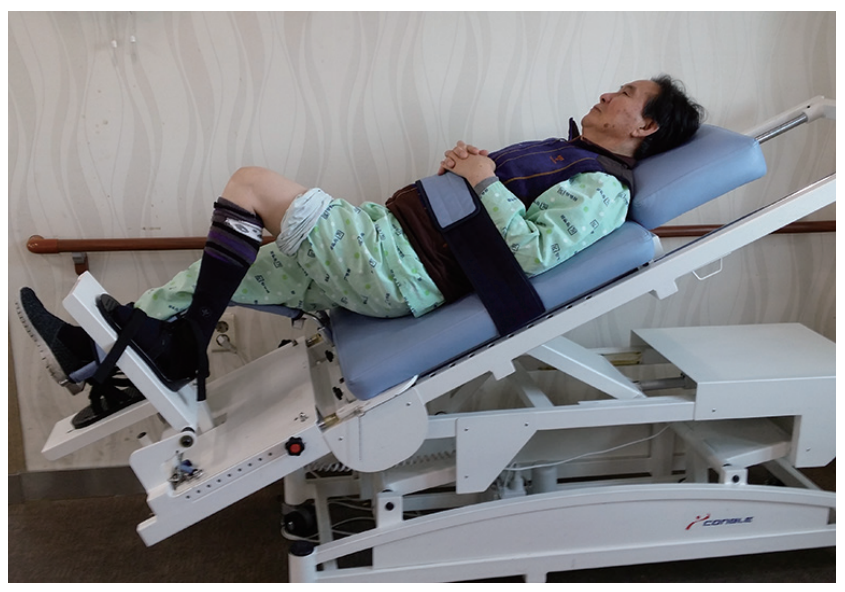

Figure 1. Sliding rehabilitation machine.

\section{2. 실험방법 및 절차}

슬라이딩 재활훈련기는 경사대에 레일 시스템 바퀴가 달린 운반대, 마비되지 않은 하지를 받쳐 발판에 닿지 않도록 하는 받침대를 설치 하였다. 유압 실린더를 장착하여 원격조절 장치로 환자나 보호자가 쉽게 경사대의 높낮이와 기울기를 조절할 수 있도록 하고, 경사대의 기울기 변화를 쉽게 알 수 있도록 각도기를 부착하였다(Figure 1). 치 료 시 하지 받침대를 이용하여 마비된 하지만으로 체중을 지탱하고 마찰을 최소화한 상태에서 슬관절 굴곡 및 신전 운동이 가능하도록 하였다. 환측 하지만으로 운동이 힘들 경우 하지 받침대를 제거하고 발판의 높이를 동일하게 조정하여 양측 하지로도 운동을 할 수 있도 록 하였다. 또한 환자의 안정성을 위해 발목 침 몸에 안전띠를 이용하 여 고정할 수 있도록 하였다. 슬관절의 굴곡 각도가 동일할 경우 경사 대의 기울기와 슬관절의 굴곡 및 신전을 반복하는 횟수로써 정량화 된 운동 강도로 훈련이 가능하도록 하였다.

슬라이딩 재활훈련기를 이용한 훈련군과 대조군 모두 보바스 치 료법을 이용한 기존의 물리치료 30 분을 실시하였으며, 훈련군은 슬 라이딩 재활훈련기를 이용한 하지근력 운동을 30 분 추가로 실시하 였다. 치료는 주 5일, 총 6주간 실시하였다.

\section{3. 측정도구 및 방법}

본 연구에서 $2 \mathrm{~m}$ 길이의 Plate 형태인 RS-scan system (RS scan Ltd., Germany)을 사용하여, 보행 시 입각기 동안 각각의 부하 방향에 따 른 발의 안정성을 평가하였다. 대상자들이 RS-scan system 위를 맨발 로 보행하는 동안 측정된 입각기 시 발바닥을 10 개의 영역으로 나누 고, 각 영역별 최고 압력값을 구하였다. 나누어진 각각의 영역(T1 (toe 1), T2-5 (toe 2-5), M1 (metatarsal 1), M2 (metatarsal 2), M3 (metatarsal 3), M4 (metatarsal 4), M5 (metatarsal 5), MF (midfoot), HM (heel medial),
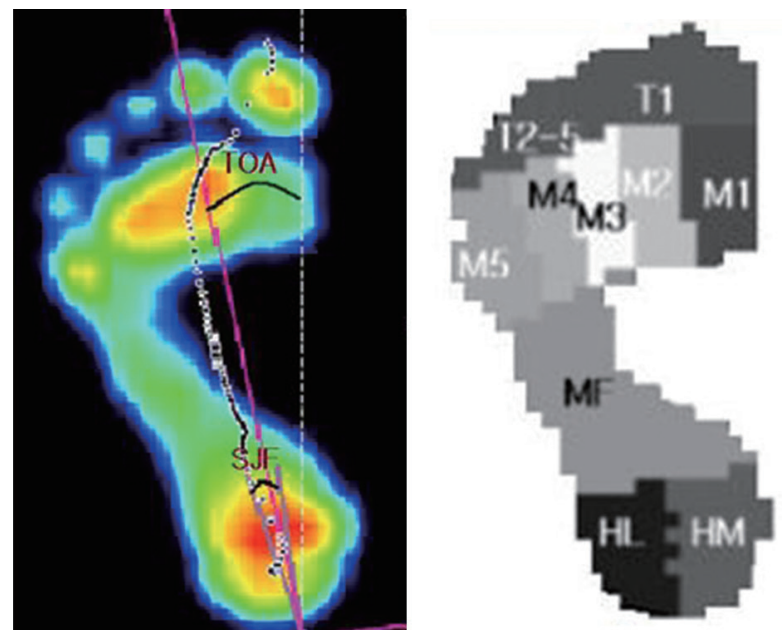

Figure 2. RS-scan. 
$\mathrm{HL}$ (heel lateral))은 다음 그림과 같다(Figure 2). 보행 시 압력 분포는 RS-scan system의 data를 해석하는 프로그램인 footscan 7 gait 2nd generation을 이용하여 $126 \mathrm{frame} / \mathrm{sec}$ 로 자료를 수집하였다.

보행 시작 전 대상자의 체중을 측정하여 프로그램에 입력하여 정 확한 족저압 측정을 하였다. 압력 측정판 위에서 움직임을 최소화한 상태에서 양발로 서도록 하여 각 대상자의 체중을 보정하였다. 보행 시 대상자는 최대한 편안한 자세로 자신의 평소 걸음걸이 자세로 걷 도록 실시하였다. 측정은 각 3 회 실시하였고, 자료 분석을 위해 마비 측 발의 족저 압력값을 사용하였다. 입각기 전체의 압력 최대 값과 최 소값의 차이를 이용하여 뒤꿈치 회전 각도(heel rotation), 엄지발가락 의 움직임(hallux movement), 발의 균형(foot balance), 중족지절 부분 의 부하(metatarsal load), 보향각, 거골하관절 축의 움직임 각도(subtalar joint angle)를 계산하였다. 뒤꿈치 회전 각도는 HM의 압력값에서 $\mathrm{HL}$ 영역의 압력값을 뺀 값으로 구하였고, 엄지발가락의 움직임은 $\mathrm{Tl}$ 영역의 압력값에서 M1 영역의 압력값을 뺀 값으로 구하였다. 발의 균 형은 $(\mathrm{M} 1+\mathrm{M} 2+\mathrm{HM})-(\mathrm{M} 3+\mathrm{M} 4+\mathrm{M} 5+\mathrm{HL})$, 중족지절 부분의 부하는 $(\mathrm{M} 2+\mathrm{M} 3)-(\mathrm{M} 1+\mathrm{M} 4+\mathrm{M} 5)$ 의 공식을 적용하여 계산하였다. ${ }^{17}$

\section{4. 자료분석}

각각의 조건에서 보행 시 입각기 족저압력을 3회 측정하여 평균한 값 을 대표값으로 사용하였다. 대상자들의 일반적인 특성을 알아보기 위하여 기술통계방법을 사용하였다. 각 군의 운동 전과 후의 유의성
검정은 대응표본 t 검정(paired t-test)을 사용하였고, 각 군 간 변화량 차이를 비교하기 위한 유의성 검정은 독립표본 $\mathrm{t}$ 검정(independent $\mathrm{t}$ test)을 사용하였다. 유의수준은 $\alpha=0.05$ 로 하였다. 본 연구에서의 모 든 자료는 평균 및 표준 편차로 제시하였고, 모든 자료는 SPSS version 18.0 버전을 사용하여 분석하였다.

\section{결 과}

\section{1. 연구 대상자의 특성}

대상자의 일반적 특징은 슬라이딩 재활훈련기를 이용한 하지근력 훈 련군은 총 15 명(남자 8 명, 여자7명)이며, 평균연령은 58.6세, 평균 발병 일은 20.2 개월, 평균 신장은 $167.4 \mathrm{~cm}$, 평균 몸무게는 $73.1 \mathrm{~kg}$ 이다. 대조 군은 총 15 명(남자 8 명, 여자 7명)이며, 평균 연령은 60.1세, 평균 발병 일은 21.32 개월, 평균 신장은 $167.4 \mathrm{~cm}$, 평균 몸무게는 $71.6 \mathrm{~kg}$ 였다. 연 구대상자의 일반적 특성에 대한 두 그룹 간 유의한 차이는 없었으며, 등분산성과 정규성을 만족하였다 $(\mathrm{p}>0.05)$.

\section{2. 발의 움직임 비교}

발뒤꿈치 회전은 훈련군에서 중재 전 $25.41 \pm 8.10 \mathrm{~N} / \mathrm{cm}^{2}$ 에서 중재 후 $22.19 \pm 7.30 \mathrm{~N} / \mathrm{cm}^{2}$ 로 유의하게 감소하였으며 $(\mathrm{p}<0.05)$ (Table 1), 대조군 에서도 중재 전 $24.49 \pm 5.65 \mathrm{~N} / \mathrm{cm}^{2}$ 에서 중재 후 $22.67 \pm 4.72 \mathrm{~N} / \mathrm{cm}^{2}$ 으로 유의하게 감소하였다 $(\mathrm{p}<0.05)$ (Table 1). 훈련군은 대조군과 비교하여

Table 1. The comparison of foot stability and motion between the training and the control groups

\begin{tabular}{|c|c|c|c|c|c|}
\hline & & Training group & Control group & $\mathrm{t}$ & $p$ \\
\hline \multirow[t]{3}{*}{ Heel rotation } & Pre & $25.41 \pm 8.10$ & $24.49 \pm 5.65$ & 0.34 & 0.74 \\
\hline & Post & $22.19 \pm 7.30$ & $22.67 \pm 4.72$ & & \\
\hline & Pre-Post & $3.22 \pm 2.03$ & $1.82 \pm 2.36$ & 1.62 & 0.12 \\
\hline \multirow[t]{3}{*}{ Hallux stiffness } & Pre & $32.83 \pm 8.43$ & $31.30 \pm 8.89$ & 0.45 & 0.66 \\
\hline & Post & $29.00 \pm 7.32$ & $29.95 \pm 7.81$ & & \\
\hline & Pre-Post & $3.83 \pm 3.98$ & $1.34 \pm 1.87$ & 2.04 & 0.06 \\
\hline \multirow[t]{3}{*}{ Foot balance } & Pre & $56.95 \pm 9.13$ & $53.09 \pm 6.51$ & 1.24 & 0.23 \\
\hline & Post & $57.16 \pm 8.60$ & $53.80 \pm 4.72$ & & \\
\hline & Pre-Post & $-0.22 \pm 2.95$ & $-0.71 \pm 5.31$ & 0.30 & 0.77 \\
\hline \multirow[t]{3}{*}{ Meta load } & Pre & $50.23 \pm 50.23$ & $51.46 \pm 3.91$ & -0.78 & 0.44 \\
\hline & Post & $53.45 \pm 4.20$ & $52.00 \pm 4.70$ & & \\
\hline & Pre-Post & $-3.22 \pm 2.64$ & $-0.53 \pm 1.46$ & -3.20 & $0.00 *$ \\
\hline \multirow[t]{3}{*}{ Toe out angle } & Pre & $23.89 \pm 4.28$ & $23.23 \pm 2.76$ & 0.30 & 0.64 \\
\hline & Post & $19.19 \pm 2.70$ & $21.82 \pm 2.73$ & & \\
\hline & Pre-Post & $4.69 \pm 2.34$ & $1.40 \pm 1.23$ & 4.47 & $0.00^{*}$ \\
\hline \multirow[t]{3}{*}{ Subtalar joint flexiblity } & Pre & $15.90 \pm 3.40$ & $16.96 \pm 2.98$ & -0.85 & 0.41 \\
\hline & Post & $13.06 \pm 3.40$ & $16.18 \pm 3.28$ & & \\
\hline & Pre-Post & $2.83 \pm 2.27$ & $0.78 \pm 1.21$ & 2.88 & $0.00 *$ \\
\hline
\end{tabular}

All values are shown in mean \pm standard deviation

*significant difference compared with the control group $(p<0.01)$. 
Table 2. The changes of foot stability and motion before and after intervention

\begin{tabular}{|c|c|c|c|c|c|}
\hline & Group & Pre & Post & $\mathrm{t}$ & $p$ \\
\hline \multirow[t]{2}{*}{ Heel rotation } & Training group & $25.41 \pm 8.10$ & $22.19 \pm 7.30$ & 5.70 & $0.00 *$ \\
\hline & Control group & $24.49 \pm 5.65$ & $22.67 \pm 4.72$ & 2.78 & 0.16 \\
\hline \multirow[t]{2}{*}{ Hallux stiffness } & Training group & $32.83 \pm 8.43$ & $29.00 \pm 7.32$ & 3.48 & 0.01 \\
\hline & Control group & $31.30 \pm 8.89$ & $29.95 \pm 7.81$ & 2.59 & 0.02 \\
\hline \multirow[t]{2}{*}{ Foot balance } & Training group & $56.95 \pm 9.13$ & $57.16 \pm 8.60$ & -0.26 & 0.79 \\
\hline & Control group & $53.09 \pm 6.51$ & $53.80 \pm 4.72$ & -0.48 & 0.63 \\
\hline \multirow[t]{2}{*}{ Meta load } & Training group & $50.23 \pm 50.23$ & $53.45 \pm 4.20$ & 4.04 & 0.01 \\
\hline & Control group & $51.46 \pm 3.91$ & $52.00 \pm 4.70$ & 1.81 & 0.20 \\
\hline \multirow[t]{2}{*}{ Toe out angle } & Training group & $23.89 \pm 4.28$ & $19.19 \pm 2.70$ & 7.21 & $0.00 *$ \\
\hline & Control group & $23.23 \pm 2.76$ & $21.82 \pm 2.73$ & 4.50 & 0.01 \\
\hline \multirow[t]{2}{*}{ Subtarlar joint flexiblity } & Training group & $15.90 \pm 3.40$ & $13.06 \pm 3.40$ & 4.51 & 0.01 \\
\hline & Control group & $16.96 \pm 2.98$ & $16.18 \pm 3.28$ & 2.32 & 0.03 \\
\hline
\end{tabular}

All values are shown in mean \pm standard deviation

*significant difference between pre- and post-test $(p<0.01)$.

발뒤꿈치 회전에서 유의한차이를 보이지 않았다( $p>0.05$ ) (Table 2).

엄지발가락의 움직임은 훈련군에서 중재 전 $32.83 \pm 8.43 \mathrm{~N} / \mathrm{cm}^{2}$ 에 서 중재 후 $29.00 \pm 7.32 \mathrm{~N} / \mathrm{cm}^{2}$ 로 유의한 감소를 보였으며 $(\mathrm{p}<0.05)(\mathrm{Ta}-$ ble 1), 대조군은 중재 전 $31.30 \pm 8.89 \mathrm{~N} / \mathrm{cm}^{2}$ 에서 중재 후 $29.95 \pm 7.81 \mathrm{~N} /$ $\mathrm{cm}^{2}$ 로 유의한 감소를 보였다 $(\mathrm{p}<0.05$ ) (Table 1). 훈련군은 대조군과 비 교하여 발의 전체적인 균형의 유의한 차이를 보이지 않았다 $(\mathrm{p}>0.05)$ (Table 2).

발의 균형은 훈련군에서 중재 전 $56.95 \pm 9.13 \mathrm{~N} / \mathrm{cm}^{2}$ 에서 중재 후 $57.16 \pm 8.60 \mathrm{~N} / \mathrm{cm}^{2}$ 로 유의한 차이를 보이지 않았으며 $(\mathrm{p}>0.05$ ) (Table 1), 대조군은 중재 전 $53.09 \pm 6.51 \mathrm{~N} / \mathrm{cm}^{2}$ 에서 중재 후 $53.80 \pm 4.72 \mathrm{~N} / \mathrm{cm}^{2}$ 로 유의한 차이를 보이지 않았다( $p>0.05$ ) (Table 1). 훈련군은 대조군과 비교하여 발의 전체적인 균형의 유의한 차이를 보이지 않았다 ( $p>0.05$ ) (Table 2).

중족지절골 부분의 압력은 훈련군에서 중재 전 $50.23 \pm 50.23 \mathrm{~N} / \mathrm{cm}^{2}$ 에서 중재 후 $53.45 \pm 4.20 \mathrm{~N} / \mathrm{cm}^{2}$ 로 유의한 증가를 보였으며 $(\mathrm{p}<0.05)$ (Table 1), 대조군은 중재 전 $51.46 \pm 3.91 \mathrm{~N} / \mathrm{cm}^{2}$ 에서 중재 후 $52.00 \pm 4.70$ $\mathrm{N} / \mathrm{cm}^{2}$ 로 유의한 증가를 보이지 않았다( $\mathrm{p}>0.05$ ) (Table 1). 훈련군은 대 조군과 비교하여 중족지절골 부분의 압력이 유의하게 증가하였다 $(\mathrm{p}<0.05)($ Table 2).

\section{3. 발의 안정성 비교}

보향각은 훈련군에서 중재 전 $23.89 \pm 4.28^{\circ}$ 에서 중재 후 $19.19 \pm 2.70^{\circ}$ 로 유의하게 감소하였으며 $(\mathrm{p}<0.05)$ (Table 1), 대조군은 중재 전 23.23 $\pm 2.76^{\circ}$ 에서 $21.82 \pm 2.73^{\circ}$ 로 유의하게 감소하였다 $(\mathrm{p}<0.05)$ (Table 1). 훈 련군은 대조군과 비교하여 보향각이 유의하게 감소하였다 $(\mathrm{p}<0.05)$ (Table 2).

거골하관절의 움직임은 훈련군에서 중재 전 $15.90 \pm 3.40^{\circ}$ 에서 13.06 $\pm 3.40^{\circ}$ 로 유의하게 감소하였으며 $(\mathrm{p}<0.05)$ (Table 1), 대조군은 중재 전 $16.96 \pm 2.98^{\circ}$ 에서 중재 후 $16.18 \pm 3.28^{\circ}$ 로 유의하게 감소하였다 $(\mathrm{p}<0.05)$ (Table 1). 훈련군은 대조군과 비교하여 거골하관절의 움직임이 유의 하게 감소하였다 $(\mathrm{p}<0.05)$ (Table 2$)$.

\section{고 찰}

발은 지지하는 기저면에 맞닿는 인체의 유일한 부위이며, 서 있을 때 신체의 가장 아래에 위치하는 구조물로 인체에서 모든 체중부하에 중요한 역할을 한다. 발의 정렬과 신경근 활동은 나머지 모든 신체부 위의 정렬과 신경근 활동에 크게 영향을 미치며, 보행에 있어 가장 중 요한 이동수단 역할을 한다.14 즉 발은 보행 시 체간 이동에 필요한 추 진력을 제공할 뿐만 아니라, 이 때 발생하는 물리적 충격을 흡수하여 불규칙한 지면에 적응하는데 기여한다. 따라서 이러한 발에서의 동 적 안정성을 측정하는 것은 다양한 활동을 수행하는 동안의 보행패 턴과 수정된 보행요소에 의해 발생하는 변화를 확인하기 위해 이용 될 수 있다. ${ }^{18}$ 본 연구는 뇌졸중 환자를 대상으로 슬라이딩 재활훈련 기를 이용한 하지근력 훈련이 발의 움직임과 안정성에 미치는 영향 을 알아보고자 실시하였다.

본 연구에서 발뒤꿈치 회전, 엄지발가락의 움직임, 발의 균형은 각 집단 간 중재 전후 변화율의 차이에서는 유의한 차이가 나타나지 않 았다. 이와 같은 결과는 기존의 보바스 방식의 치료 훈련으로도 발의 움직임에 있어 비슷한 효과를 나타낸다는 의미로 해석할 수 있다.

발과 경골을 연결하는 거골하관절에서 발생하는 회내와 회외가 과도하게 발생하면 역학적 커플링에 따라 경골 역시 보상적인 과도한 내측, 외측 경골 회전이 발생되고, 이는 무릎 관절의 정상적인 수평면 회전을 벗어나게 하여 무릎 관절에 이상이 발생하게 된다. Scott와 
Winter ${ }^{19}$ 는 거골하관절의 정상 범위는 움직임 방향을 기준으로 $0-16^{\circ}$ 라고 하였는데 본 연구에서 슬라이딩 재활훈련기를 이용한 하지근 력 훈련군이 대조군과 비교하여 보행 시 거골하관절의 범위가 유의 하게 감소하였다. 거골하관절의 운동 범위 증가는 발목 염좌의 위험 성을 높이고 역학적인 에너지 소모를 늘리게 되는데 ${ }^{14}$ 본 연구에서 슬라이딩 재활훈련기를 이용한 하지근력 훈련은 발과 발목에 지속적 인 압력을 제공하여 고유수용성 감각 입력에 효과이며, ${ }^{13}$ 그중에서 도 발목은 체중부하 과정에서 하지 근육의 기능과 협력 작용을 통해 신체를 지지해주며, 신체의 자세유지에 대한 감각되먹임을 촉진하여 발과 발목의 동적 안정성이 증가되어 결과적으로 거골하관절의 운 동 범위가 감소한 것으로 생각되어진다. 또한 슬라이딩 재활훈련기를 이용한 운동은 장단지근의 길이 변화를 발생시키며, ${ }^{20}$ 변화된 길이는 근방추와 골지건기관에서 발생하는 구심성 정보의 입력을 증가시키 게 될 뿐만 아니라 전경골근의 근 활성도 또한 증가되어 나타난 결과 로 생각되어진다. Lee와 $\mathrm{Bae}^{14}$ 는 정상 성인을 대상으로 보행 시 부하의 위치에 따른 발의 동적 안정성을 알아본 결과 일반적인 보행 시에 앞 쪽과 뒤쪽 부하 시 보다 거골하관절의 더 작은 범위로 움직여 본 연구 와 일치함을 보였다.

발의 위치는 보행 동작에 있어 가장 중요한 부위 중 하나이다. 그 중 보향각은 지지단계 동안 하지의 내적 또는 외적 회전의 정도를 나 타내주며 고관절의 움직임, 경골과 복사뼈의 뒤틀린 정도 그리고 하 지의 구조적 비정상적인 상태 등에 의해 영향을 받는다. 또한 정상적 인 보행을 하기 위하여 7-18를 유지하는 보향각이 중요한 역할을 한 다. Hwangbo 등 20 은 발목 각도가 증가함에 따라 종경골각과 대퇴사 두근각이 증가하며 이는 발목각도가 보행에 큰 영향을 미치는 요인 이라고 하였다. 본 연구에서는 슬라이딩 재활훈련기를 이용한 하지근 력 훈련군은 운동하는 동안 관절 내 압력의 증가와 루피니 신경종말 에 의해 관절 내낭이 압력변화에 민감하게 반응하며, ${ }^{21,22}$ 증가 되어진 하지의 신전근은 신체의 안정성을 증가시키고, 그로 인해 증가되어졌 던 체중지지면이 줄어들어 발뒤꿈치 회전이 감소하면서 보향각도 감 소되어진 것으로 생각되어진다. Lee와 Bae ${ }^{14}$ 는 뒤쪽 또는 부하를 적용 하지 않았을 때가 앞쪽 부하 적용 시보다 보향각이 더 감소하여 본 연 구와 일치함을 보였다. 또한 Kim등23은 트레드밀 보행훈련군과 불안 정면 보행훈련군의 마비측 보향각이 대조군과 비교하여 유의하게 감 소하여 본 연구와 일치함을 보였다.

또한 중족지절골 부분의 부하는 보행 시 장애물 높이에 따른 정상 인의 족저압 분포 연구에 따르면 장애물의 높이가 높아질수록 발허 리 부분에 하지의 압력 중심이 머문다고 하였다. ${ }^{2}$ 본 연구에서는 슬 라이딩 재활훈련기를 이용한 하지근력 훈련군에서 대조군과 비교하 여 중족지절골의 족저압력이 유의하게 증가하였다. 이는 슬라이딩 재활훈련기를 이용한 하지근력 훈련군은 운동을 시행하는 동안 발
을 지면에 고정하여 무릎관절의 구심성과 원심성 수축을 수행하게 되는데 이러한 훈련방법은 신체인식력을 증가시키며, 체중부하의 민 감도에 의해 마비측 하지의 신전근이 활성화되어 중족지절골의 족저 압력이 증가된 것으로 생각되어진다. Koo와 $\mathrm{Kim}^{25}$ 은 노인 대상자들 의 Rollator 사용은 중족 지절 부분의 부하를 유의하게 증가시키며, 제 한된 지지면의 면적을 넓혀 유각기의 발이 추진하는 동안에도 체간 의 중심이 지지면 상에서 유지되도록 조절하는 것을 돕는다고 하였 다. 즉 중족 지절 부분의 부하가 증가함으로 불안정성을 방지하고 평 형을 회복하여 본 연구결과와 일치하였다.

결론적으로, 슬라이딩 재활훈련기를 이용한 하지근력 훈련은 뇌 졸중 환자의 거골하관절의 운동 범위와 보향각을 감소시킬 뿐만 아 니라 중족지절골의 족저압력을 증가시켜 뇌졸중 환자의 발의 안정성 을 증진시킨다. 이러한 결과는 슬라이딩 재활훈련기를 이용한 하지 근력 훈련이 뇌졸중 환자의 발과 발목의 안정성과 운동성을 증가시 켜 보행능력의 많은 요소에 영향을 끼쳐, 환경의 변화와 다양한 과제 에 대한 적절한 반응을 만들어 낼 수 있음을 의미하며, 이러한 연구 결과를 통하여 임상에서도 적극적으로 활용될 수 있을 것이라 생각 되어진다.

하지만 본 연구는 많은 수의 대상자를 포함시키지 못하였으며, 실 험군에만 30 분동안 추가적인 운동을 시행하여 연구결과를 일반화 하기에는 제한이 따르며, 연구에 참여하기 이전 어떤 치료를 받았는 지 고려하지 않았고, 병변의 종류와 부위, 그리고 환자 개개인의 다리 길이 등을 고려하지 못하였다. 또한 연구가 단기간 시행되었기 때문 에 장기적인 효과를 평가할 수 없었고, 실험에 참가한 대상자들의 치 료시간 이외의 환경을 통제할 수 없었다. 향후 이러한 제한점을 보완 하여 뇌졸중 환자의 치료에 유용한 중재 프로그램을 개발, 보급하여 야 할 것으로 생각되어지며, 앞으로의 연구에서는 보행을 측정할 수 있는 다양한 추가적인 측정이 필요하다고 생각되어진다.

\section{REFERENCES}

1. Kim MH, Lee WH, Yun MJ. The effects on respiratory strength training on respiratory function and trunk control in patient with stroke. J Kor Phys Ther. 2012;24(5):340-7.

2. Choi AY, Cho WS. The effects of mechanical horseback riding exercise on the dynamic balance in patients with cerebral infarciton. J Kor Phys Ther. 2014;26(2):123-9.

3. Kim JH. A study on the correlation between static, dynamic standing balance symmetry and walking function in stroke. J Kor Phys Ther. 2012;24(2):73-81.

4. Shim HB, Cho HY, Choi WH. Effects of the trunk stabilization exercise on muscle activity in lumbar region and balance in the patients with hemiplegia. J Kor Phys Ther. 2014;26(1):33-40.

5. Weiss A, Suzuki T, Bean J, et al. High intensity strength training improves 
strength and functional performance after stroke. Am J Phys Med Rehabil. 2000;79(4):369-76.

6. Ouellette MM, LeBrasseur NK, Bean JF, et al. High-intensity resistance training improves muscle strength, self-reported function, and disability in long-term stroke survivors. Stroke. 2004;35(6):1404-9.

7. Kim CH. The effects of whole body vibration exercise on balance and lower exteremity muscle activity in stroke patients. J Kor Phys Ther. 2013;25(5):266-72.

8. Krebs DE, Scarborough DM, McGibbon CA. Functional vs. Strength training in disabled elderly outpatients. Am J Phys Med Rehabil. 2007; 86(2):93-103.

9. Sharp SA, Brouwer BJ. Isokinetic strength training of the hemiparetic knee: Effects on function and spasticity. Arch Phys Med Rehabil. 1997; 78(11):1231-6

10. Brown DA, Nagpal S, Chi S. Limb-loaded cycling program for locomotor intervention following stroke. Phys Ther. 2005;85(2):159-68.

11. Flansbjer UB, Miller M, Downham D, et al. Progressive resistance training after stroke: Effects on muscle strength, muscle tone, gait performance and perceived participation. J Rehabil Med. 2008;40(1):42-8.

12. Cramp MC, Greenwood RJ, Gill M, et al. Low intensity strength training for ambulatory stroke patients. Disabil Rehabil. 2006;28(13-14):883-9.

13. Jan MH, Lin CH, Lin YF, et al. Effects of weight-bearing versus nonweight-bearing exercise on function, walking speed, and position sense in participants with knee osteoarthritis: A randomized controlled trial. Arch Phys Med Rehabil. 2009;90(6):897-904.

14. Lee SY, BaeSS. The studies on the foot stability and kinesiology by direction on carry a load during gait. J Kor Phys Ther. 2009;21(1):97-101.
15. Jang KH, Heo JY. Footwear design. Seoul, chohyong publishing company, 1992.

16. No JS, Kim TH. Reliability of plantar pressure measures using the parotec system. Physical Therapy Korea. 2001;8(3):35-41.

17. D'Aout K, Lescrenier K, Gheluwe BV, et al. Advances in plantar pressure measurements in clinical and scientific research. Maastiricht, Shaker, 2008.

18. Shu L, Hua T, Wang Y, et al. In-shoe plantar pressure measurement and analysis system based on fabric pressure sensing array. IEEE Trans Inf Technol Biomed. 2010;14(3):767-75.

19. Scott SH, Winter DA. Talocrural and talocalcaneal joint kinematics and kinetics during the stance phase of walking. J Biomech. 1991;24(8):743-52.

20. Hwangbo G, Lee JH, Chung HK, et al. Effect of step width and toa on qangle and cta in walking. J Kor Phys Ther. 1996;8(1):33-47

21. Refshauge KM, Fitzpatrick RC. Perception of movement at the human ankle: Effects of leg position. J Physiol. 1995;488(1):243-8.

22. Wood L, Ferrell WR. Response of slowly adapting articular mechanoreceptors in the cat knee joint to alterations in intra-articular volume. Ann Rheum Dis. 1984;43(2):327-32.

23. Kim EJ, Hwang BG, Kwon HC. The effects of gait component and foot plantar pressure on gait training way in stroke patients. The Journal of Rehabilitation Science. 2009;27(2):41-54.

24. Han JT, Lee MH, Kim K. The study of plantar foot pressure distribution during obstacle crossing with different hight in normal young adults. Korean Journal of Sport Biomechanics. 2008;8(2):1-9.

25. Koo HM, Kim MH. The effect of a rollator on plantar pressure and foot balance during gait in old-aged adults. J Kor Phys Ther. 2010; 22(5):71-6. 